\title{
Pobreza y exclusión social desde la perspectiva de género
}

\author{
Ignasi Brunet Icart \\ Universitat Rovira i Virgili \\ ignasi.brunet@urv.cat
}

\section{Resumen}

El objeto de reflexión de este artículo es, en el contexto de generización de los conceptos de pobreza y exclusión social, el de acotar o definir el concepto de género, $y$ distinguir entre las dos aproximaciones existentes: la primera, orientada a analizar la denominada feminización de la pobreza, que bizo fortuna a fines de la década de 1990, y la segunda, que analiza la pobreza y la exclusión social desde una perspectiva de género.

Palabras clave: género, exclusión social, pobreza.

\begin{abstract}
The aim of this article is, in the context of the genderization of the concepts of poverty and social exclusion, to delimit or define the concept of gender and distinguish between the two existing approaches: the first focuses on analyzing the so-called feminization of poverty that was in vogue at the end of the 1990s, and the second analyzes poverty and social exclusion from the perspective of gender.
\end{abstract}

Key words: gender, social exclusion, poverty 


\section{Introducción}

La "feminización de la pobreza» como aumento de la pobreza entre las mujeres es una ortodoxia global que ya nadie pone en cuestión. Sin embargo, las diversas medidas históricas que se han tomado para hacerle frente han pasado por encima del hecho de que ésta deba analizarse desde una perspectiva de género o feminista. Además, esta expresión pone de manifiesto que teórica y empíricamente la cuestión está en que los trabajadores, pobres y excluidos, no son un ente neutro, sino que tienen un género, y que las medidas para erradicar la pobreza, al estar centradas en unidades de análisis estatales o, en el mejor de los casos, familiares, no se han planteado el problema de lo que sucedía dentro de la unidad doméstica, careciendo así de los instrumentos básicos para adoptar una perspectiva feminista. Este es un aspecto importante si tratamos las injusticias de distribución y de reconocimiento que afectan al género femenino, en el sentido de que, por ejemplo, su falta de reconocimiento actúa como elemento de subordinación social y de explotación económica. Una subordinación y explotación que la sociedad industrial camufló remitiéndolos al campo de la naturaleza; de ese modo, ha podido explotar el trabajo femenino tanto en sus funciones asignadas (reproductivas) como en las toleradas (productivas) a partir de una presunta condición natural que inclinaría a las mujeres al autosacrificio y a una adopción no cuestionada de los roles establecidos. Una adopción sin la cual resulta inexplicable el hecho de que en el mundo actual casi todos los trabajos considerados femeninos mantienen a las trabajadoras dentro de los límites de la pobreza.

Por tanto, si nos aproximamos al estudio de la pobreza sin tener en cuenta la categoría de género, y concretamente las construcciones identitarias de género, no seremos capaces de estimar la incidencia real de la pobreza y la exclusión social en la población, ni mucho menos conocer los principales factores que las provocan. Además, las estrategias que propongamos para hacer frente a la pobreza resultarán ineficaces para una parte de la población, e incluso las políticas de lucha contra la pobreza pueden llegar a empeorar las condiciones de vida de las mujeres empobrecidas. Esto es clave en tanto en cuanto la "feminización de la pobreza» no está reflejada en las mediciones convencionales; de hecho, cuando se producen cuantificaciones de la misma no se introduce un elemento fundamental para explicar dicha feminización, a saber, la posición de las mujeres en la estructura social y su vulnerabilidad estructural, que se padece a partir de una relación social desigual, de marcada asimetría de poder.

Desde un punto de vista conceptual y empírico, la vulnerabilidad estructural de las mujeres es consecuencia de su dominación real, que se ha ejercido y se ejerce a partir del modelo de la dominación masculina, es decir, del poder normativo masculino en la determinación de las conductas y los roles de género, así como en su valoración. Este 
poder masculino se desarrolló con la división sexual del trabajo («la jerarquización de la diferencia de género») y, en general, a la que hoy se entiende como androcentrismo ("supremacía masculina»), y que presenta un carácter estructurante al involucrar necesariamente la producción de sujetos generizados masculinos y femeninos, que asumen identidades sociales y prácticas diferenciadas según una específica división sexual del trabajo, lo que constituye un dispositivo sociopolítico que coloca a varones y mujeres en "papeles fijos y jerarquizados» («la ideología de los estereotipos de género») basados en el determinismo de las diferencias biológicas («la mujer es ensalzada por sus virtudes como madre y esposa, y proclamada reina del hogar»).

Este dispositivo de distribución no igualitario da cuenta de la presencia de las mujeres en el mercado de trabajo en condiciones cualitativas muy específicas, esto es, mayoritariamente: 1) como trabajadores mal pagados por la falta de equidad entre los géneros para la relación trabajo-salario (no se cumple, entre varones y mujeres, que a igual trabajo se reciba igual salario); 2) como trabajadores de servicios "feminizados" y en ocasiones sexualizados: secretarias, trabajadoras domésticas, prostitutas, azafatas, etc.; 3) en trabajos derivados de la cualidad "maternal" concebida como innata por el biologicismo ideológico: enfermeras, asistentas sociales, maestras; 4) como blancos del acoso sexual (basado en la relación de dependencia respecto del acosado); 5) como trabajadoras a media jornada debido a la necesidad de cumplir con la crianza de los hijos, y como trabajadoras de doble jornada (doméstica no remunerada y pública remunerada);6) como «esposas que trabajan» $y$ «madres que trabajan»; 7) como esposas y madres en primera instancia que, en segunda, también "salen a trabajar»; 8) como las que ganan un «ingreso extra».

Lo que revelan todas estas condiciones, acentuadas además en un contexto laboral en el que el pleno empleo ha dejado de ser ya un objetivo de la política económica, es que la asimetría de género es intrínseca a la institución histórica del capitalismo, y no incidental, porque se establece sobre las premisas de la separación entre trabajo asalariado y el Estado por una parte, y la crianza femenina de los hijos y el trabajo doméstico invisible y no remunerado en el hogar, por otra. En cualquier caso, la vulnerabilidad estructural de las mujeres constituye un referente necesario para entender la división sexual de las tareas, de los tiempos y de los espacios, de los deberes y de los derechos, y para levantar, además, acta del androcentrismo de las ciencias en general, y de las ciencias sociales en particular; unas ciencias que se caracterizan, en términos generales, por una histórica represión fundamental de las asimetrías de género al discurrir sobre la base de un sujeto "hombre» que incluye, y a la vez borra, a la «mujer».

Esa es la cualidad que se ha llamado homologizante/incluyente de un sujeto universal diferenciado desde el punto de vista de género, y que es producido en realidad como un sujeto masculino trabajando representaciones del mundo orientadas a 
sí mismo. De ahí que De Lauretis (1987) afirme que "con 'la mujer' hago referencia a una construcción ficticia, un destilado de los discursos, diversos pero coherentes, que dominan en las culturas occidentales (discursos críticos y científicos, literarios o jurídi$\cos$ ), que funciona a la vez como su punto de fuga y su peculiar condición de existencia. Del mismo modo, la mujer, lo-que-no-es-el-hombre (Naturaleza y Madre, sede de la sexualidad y del deseo masculino, signo y objeto del intercambio social masculino) es el término que designa a la vez el punto de fuga de las ficciones que nuestra cultura se cuenta a sí misma y la condición de los discursos en los que están representados esas ficciones.»

\section{El concepto de género}

La categoría "género» surgió en la teorización feminista en la década de 1970 y permite subrayar, por un lado, la ocultación de la diferencia entre los sexos bajo la neutralidad de la lengua y, por otro, poner de manifiesto el carácter de construcción sociocultural de esa diferencia. Habitualmente, señala Tubert (2003a: 8), se entiende que el sexo corresponde "al plano biológico, en tanto que el género es el producto de la construcción sociocultural. El problema es que esta polaridad no hace más que reproducir la oposición naturaleza-cultura y el dualismo cuerpo-mente que han marcado al pensamiento occidental desde sus orígenes. Por una parte, se supone que esta oposición se corresponde con una diferencia real, aunque es producto de una operación cultural que establece artificialmente límites dentro de un continuo; por otra, se desconoce que es imposible distinguir en el sujeto aquello que resulta de su condición biológica y aquello que ha sido generado por su formación en el seno de un universo humano, lingüístico, cultural».

Por otra parte, la década de 1970 se caracterizó por una gran turbulencia epistemológica, lo que supuso un debate en el que el feminismo comenzó a tener no sólo voz propia, sino también aliados académicos y políticos en la afirmación del patriarcado como matriz que configura la identidad, así como la inserción en lo real de hombres y mujeres. Las feministas, mediante la categoría patriarcado, se percataron de que aunque el capitalismo necesita a "alguien» que se quede en la esfera privada y compre todo lo que el mercado ofrece para esta esfera, no necesita que ese «alguien» sean precisamente las mujeres; quien sea ese "alguien» es algo que la estructura del capitalismo deja indeterminado. El que de esa variable se ocupen las mujeres es algo que sólo se explica gracias a la existencia del patriarcado.

La categoría género ha permitido, entonces, no sólo denunciar la opresión y dominación sexual, sino que es una variable a considerar cuando se analiza el patriarcado, 
y que Molina (2003) define como el poder de asignar espacios, no sólo en su aspecto práctico, colocando a las mujeres en lugares de sumisión, sino en su aspecto simbólico; es decir, nombrando y valorando esos espacios como «lo femenino». El patriarcado "sería entonces una suerte de 'topo-poder' androcéntrico que se confunde, en cierto sentido, con el 'todo-poder'. El género sería la operación y el resultado de ejercer este poder del patriarcado de asignar los espacios - restrictivos - de lo femenino mientras se constituye lo masculino desde el centro, como lo que no tiene más límites que lo negativo, lo abyecto o lo poco valorado» (Tubert, 2003a: 22).

El patriarcado constituye, pues, un sistema de organización social basado en el control y la dominación sobre las mujeres, lo que ha permitido, por un lado, hacer irracionales las identidades de género y desarticular las relaciones ilegítimas de poder, $y$, por otro, racionalizar la justicia sexual al mostrar ésta los mecanismos de justicia o injusticia en cualquier sociedad dada o en cualquier contexto histórico conocido. En otras palabras, "no puede haber justicia social sin justicia sexual. La injusticia sexual aborda principalmente la injusticia del poder sexual y la división sexual del trabajo. La justicia sexual considera que sin una redefinición social en torno a los sexos, basada en el reconocimiento, las instituciones seguirán reproduciendo ideologías, normas y estereotipos desiguales a mujeres y varones» (Miyares, 2003: 31).

Para Miyares (2003:36), asumir la justicia sexual implica cuestionar "por qué una sociedad ha de esperar una cosa distinta de mujeres y varones: no somos más libres especificando normativas y valores diferenciados por el sexo. La justicia sexual denuncia que la apelación al sexo para fundamentar la situación $\mathrm{x}$ es una discriminación más o menos encubierta", y es que el poder de cualquier mujer está coartado por la determinación genérica, que funciona encarnado por un solo sujeto y con todo su enorme trasfondo normativo, sin casi restricción. No es posible, entonces, hablar de imparcialidad de las leyes porque el poder ha sido uno, el masculino, el patriarcal.

Además, la justicia sexual demuestra que las sociedades patriarcales están articuladas de forma tal que su entramado institucional y todas sus estructuras sociales tienen como finalidad reproducir este modo de dominación, esto es, esta injusticia sexual; en otras palabras, perpetuar el reconocimiento social de las desigualdades de género, desigualdades que atraviesan otras determinaciones socio-estructurales, tales como la clase, la edad, la etnia, la opción sexual, la posición en el sistema mundial, etc. Por ello, dado que las diversas formas de estratificación social se interrelacionan en la vida de las mujeres, no se puede omitir en el análisis de la estratificación social el plano de las relaciones de género, que están claramente cruzadas por las de clase, raza, etnia, edad, opción sexual, etc., dado que es la posición de clase, la pertenencia étnica, la opción sexual de la mujer lo que acaba estructurando el significado concreto que el género tiene para ella. En este sentido, el feminismo «negro»o «multirracial» hace ya tiempo que 
tiene bien claro que carece de sentido referirse a un sujeto femenino genérico, puesto que el plano de lo femenino es un ámbito internamente fragmentado.

Butler (2001a) explica, por un lado, cómo el género opera como una construcción reguladora que privilegia la heterosexualidad. Para ello, plantea el género como una función cultural, un efecto performativo de actos reiterativos, donde el género se define en cada acto. No existe, por lo tanto, nada auténtico en relación con el género, no existe un "centro» que produzca los signos reafirmadores del género. Por lo demás, Butler sostiene que, si aceptamos que el sexo no se reduce a ser una entidad anatómica, cromosómica, hormonal, supuestamente natural, sino que la dualidad de los sexos "se establece a través de una historia, de una genealogía que presenta las oposiciones binarias como una construcción variable, y que los hechos supuestamente naturales del sexo se producen por medio de discursos científicos al servicio de otros intereses políticos y sociales, habremos de concluir que la categoría sexo es una construcción cultural en la misma medida que el género. Para el ser humano, el sexo natural, entendido como realidad prediscursiva, previa a la cultura, no es sino un producto de los discursos y prácticas sociales, aunque no se lo construye como lo no construido» (Tubert, 2003b:9).

Para Butler (2005), la diferencia sexo/género pierde su significación, porque no tiene sentido definir al género como la interpretación cultural del sexo si el sexo mismo se entiende como una categoría del género. Por tanto, hay que ir más allá del dualismo sexo/género, pues no tiene sentido epistemológico ni político, y de los conceptos esencialistas que suelen acompañar a las teorías centradas en el género como concepto explicativo. Además, en palabras de Butler (2001b), el género no es exhaustivo, "no es coherente o consistente en contextos históricos distintos»; su significado se construye invariablemente en relación con las modalidades raciales, de clase, étnicas, sexuales y regionales de cada situación. Por consiguiente, el género es una "relación entre sujetos socialmente constituidos en contextos específicos», de ahí que desde la denominada política de la localización se defina el género no como una construcción binaria y monolítica, sino como una marca de una posición de subordinación que está cualificada por otras variables de opresión. Al respecto, Scott (2000) argumenta la necesidad de sustituir género por mujeres, pues género no comporta una declaración necesaria de desigualdad o de poder, ni nombra al bando (hasta entonces invisible) oprimido. Mientras que el término «historia de las mujeres» proclama su política al afirmar (contrariamente a la práctica habitual) que las mujeres son sujetos históricos válidos, "género» incluye a las mujeres sin nombrarlas, y así parece no plantear amenazas críticas.

Se puede entender, a la manera de Foucault (1991), que el sujeto no es una sustancia, sino una forma, una forma que no es siempre idéntica a sí misma, lo que significa que en cada caso se establecen, respecto a uno mismo, formas de relaciones diversas, insertas en diferentes relaciones de poder. Por otra parte, el género, inserto en una 
compleja red de relaciones de poder, no es el único determinante de la identidad de un sujeto y, al mismo tiempo, su forma concreta depende de esa red. Esta idea se capta con una poderosa imagen, la de la matriz del género, en la cual se insertan, en interrelación, múltiples ejes de poder como mediaciones sociales en la conformación de la identidad. Cada dimensión implica una subjetividad significativa determinada que puede matizar, reforzar o desdibujar las otras.

A este complejo proceso De Lauretis (2000) lo denomina "tecnología del género", intentando captar la multiplicidad de diferencias entre mujeres, pero también en las mujeres - es decir, la no unidad de las identidades colectivas y tampoco de las individuales-. Puede ser, argumenta De Lauretis (1987:8), «un punto de arranque pensar el género en paralelo con las líneas de la teoría de la sexualidad de Michel Foucault, como una 'tecnología del sexo' y proponer que, también el género, en tanto representación o auto-representación, es el producto de variadas tecnologías sociales — como el cine- y de discursos institucionalizados, de epistemologías y de prácticas críticas, tanto como de la vida cotidiana. Podríamos decir entonces que, como la sexualidad, el género no es una propiedad de los cuerpos o algo originariamente existente en los seres humanos, sino el conjunto de efectos producidos en los cuerpos, los comportamientos y las relaciones sociales, en palabras de Foucault, por el despliegue de una tecnología política compleja.»

Por otra parte, De Lauretis $(1987: 18)$ da cancha a la propuesta de las tecnologías con una noción que es muy característica de la tradición feminista teórica y política: la experiencia de las mujeres, la cual entiende como "comprensión de la propia condición personal en tanto mujer en términos sociales y políticos y la constante revisión, revaluación y reconceptualización de esa condición en relación con la comprensión de otras mujeres de sus posiciones sociosexuales"»

Las variaciones que existen entre mujeres de diferentes clases, orientaciones sexuales y orígenes étnicos son tan importantes para la posición social de la mujer como los elementos comunes inherentes al hecho de ser una mujer dentro de una sociedad determinada. Por lo tanto, hay que situar a hombres y mujeres en numerosos sistemas de dominación, y explicar por qué hay mujeres y hombres que lo tienen todo, y mujeres y hombres que no tienen nada. De un modo más específico, no todos los individuos se encuentran igualmente vulnerables, ya que de la serie de fenómenos que resultan ser factores estructurales generadores de la exclusión social, no todos afectan por igual a toda la población. En el contexto europeo, las personas más vulnerables son los jóvenes, los discapacitados, los inmigrantes y los mayores de 45 años. Por lo tanto, no se puede hablar de pobreza y exclusión como algo uniforme, y aunque las mujeres están en mayor riesgo de pobreza y exclusión, es necesario considerar que hablar exclusiva- 
mente de dos géneros contribuye a la esencialización de las diferencias y a ignorar la complejidad de las identidades sexuales y sociales posibles.

Por otra parte, cabe destacar que «el gran avance llevado a cabo por el estructuralismo fue el reconocimiento del carácter relacional de toda identidad social; su límite fue la transformación de esas relaciones en un sistema, en un objeto identificable e inteligible (es decir, en una esencia)» (Laclau, 1993: 104). Al renunciar a fijar esas identidades en un sistema, no queda alternativa más que la de admitir una definición de lo social como juego infinito de las diferencias. Por lo tanto, «lo social es además el intento de ordenar, regular y disciplinar ese "juego infinito de las diferencias" y abarcarlo "dentro de la finitud de un orden" pero que ya no puede concebirse como 'totalidad fundante', es decir, esencia subyacente» (Cháneton, 2007: 66).

No se puede olvidar, entonces, relacionar el género con otras categorías que informan de las relaciones sociales y de las formas culturales, y es que el gran error de la feminista de clase media es dar por supuesto que, con independencia del origen de clase, opción sexual y origen étnico, la experiencia de la discriminación es la misma, como si en realidad existiera la "mujer genérica", y como si en realidad existiera un dato a priori - el sexo- previo a su denominación, esto es, a una lectura interesada de los cuerpos que toma los datos físicos de éstos como causa de las prácticas sociales y no como efectos de procesos sociales que instituyen dispositivos disciplinarios que forman a los propios cuerpos en algo relevante desde el punto de vista de la clasificación jerárquica de los sexos y/o géneros.

Ante esta jerarquización, no hay otra alternativa que el cuestionamiento y la desidentificación en los mandatos y asignaciones de la «tecnología del género». Como también hay que cuestionar los modos a través de los cuales las mujeres son construidas en los procesos étnicos y nacionales, tal y como se ha venido desarrollando en el feminismo poscolonial, que se define como un conjunto amplio de trabajos que examinan la condición histórica de las mujeres en los países liberados de su dominación colonial después de la II Guerra Mundial. Estos trabajos abandonan el postulado de que el poder sería de una clase que lo habría conquistado. Para Foucault (1983), el poder no es una propiedad, sino una estrategia, y sus efectos no son atribuibles a una apropiación, sino a dispositivos históricos. Esto no implica, desde luego, negar la existencia de las clases, sino afirmar que el poder no proviene de su posesión por una clase sino que es un «efecto de conjunto de sus posiciones estratégicas». El poder carece de homogeneidad, aunque logra efectividad debido a los puntos singulares por los que pasa. De hecho, las diferencias de género/clase/generación/etnia constituyen ocasiones para el pasaje o puntos de apoyo del poder en el marco de situaciones estratégicas particulares, por lo cual deben abandonarse los escenarios teóricos que localizan el poder como propiedad exclusiva de sujetos empíricos «varones». 
El feminismo poscolonial constituye un feminismo crítico de la lógica de dominio mundial que genera un centro (el Imperio) y una periferia (las colonias) vinculados entre sí por un movimiento expansionista, regulado desde dentro de las fronteras del Imperio por un discurso social que marca el lugar de la experiencia efectiva de la marginalidad, a la vez que permite su transformación en experiencia crítica. Un feminismo también crítico con las voces particularistas o relativistas, dado que se ha pasado de la "misión civilizadora» a, en la actualidad, un respecto extremo de todas las diferencias culturales que impide cualquier pauta de acción medianamente generalizable. Como indica Tortosa (2001b), tal vez sea exagerado ver en esta posición un recurso de desresponsabilización por parte de los países centrales, que sí crearon la pobreza en las periferias y ahora pretenden que luchar contra la pobreza es universalismo poco respetuoso.

No obstante, en la actualidad el reto consiste en encontrar indicadores dinámicos sobre el empobrecimiento y la exclusión social que tengan en cuenta las condiciones territoriales (locales y regionales), que puedan ser comparados internacionalmente y que recojan las formas de exclusión basadas en el género observables en las unidades domésticas, sin por ello perder de vista otras dimensiones de desigualdad, así como la dimensión política del Estado, que no deja de ser un efecto de conjunto o una resultante de una multiplicidad de engranajes y de núcleos que se sitúan a un nivel completamente distinto y que constituyen una «microfísica del poder». Las sociedades modernas "son sociedades 'disciplinarias' pero la disciplina no puede identificarse con una institución o un aparato, sino que atraviesa los aparatos y los hace converger, los prolonga de otra manera, bajo la forma de redes. La micropolítica de género/clase/ etnia se entiende entonces como multiplicidad de relaciones de fuerza inmanentes al dominio en el que se inscriben» (Cháneton, 2007:61).

\section{De la feminización de la pobreza a los estudios de género}

En el contexto de generización de los conceptos de pobreza y exclusión social, se destacan dos aproximaciones:

1) La primera orienta su estudio hacia la feminización de la pobreza, que hizo fortuna a finales de la década de 1990 y que sigue utilizándose en la actualidad en investigaciones de ámbito internacional. Se trata de una perspectiva que constata que las mujeres son más pobres que los hombres, y el concepto de feminización se utiliza para indicar que la pobreza tiene una mayor incidencia en la mujer que en el hombre, o que la pobreza de las mujeres es más severa que la de los hombres, o que la incidencia sobre 
las mujeres está creciendo en comparación con los hombres. Pero la expresión feminización de la pobreza no deja de ser una fórmula vacía, ya que se adopta como si tuviera un contenido suficiente y reconocido, cuando únicamente señala que la proporción de mujeres sobre el total de pobres ha aumentado. Por consiguiente, la feminización de la pobreza se debe analizar desde el tipo de familia y su estructura, ya que en ésta radica la base del problema; una institución familiar que todavía hoy no considera imprescindible dotar de las mismas oportunidades educativas a los hijos y las hijas, que se resiste a que las mujeres trabajen fuera de la unidad familiar y que concibe las tareas del hogar como trabajo gratuito. En otras palabras, esta perspectiva sitúa a los hombres en el ámbito de la producción de riqueza y a las mujeres en el ámbito de la reproducción social.

2) La segunda orienta su estudio a la relación entre el proceso de empobrecimiento y el género, pues la pobreza no siempre se ha analizado desde una perspectiva de género. Antes de que las feministas contribuyeran al análisis, se consideraba que la población pobre estaba íntegramente formada por hombres, o bien se daba por sentado que las necesidades e intereses de las mujeres eran idénticos a los de los hombres, jefes del hogar, y por ende podían supeditarse a ellos.

En las tres últimas décadas, la investigación y el activismo feminista han logrado ver que las mujeres son pobres en tanto en cuanto esta situación está condicionada por el género; en otras palabras, la experiencia de la pobreza y exclusión está condicionada por las identidades de género. Esto significa que hombres y mujeres son definidos como seres humanos diferentes, cada uno de ellos con sus propias oportunidades, roles y responsabilidades. Y ello tiene que ver con la división del trabajo, que es fundamentalmente división sexual, observable no únicamente en el vínculo entre la feminización de la fuerza de trabajo y el empeoramiento de las condiciones de trabajo, sino también en el contenido y las condiciones de trabajo de hoy.

Estas condiciones han sido impuestas tras violentas reestructuraciones, que no son más que la extensión paulatina de las características del trabajo, tanto asalariado como no asalariado, estructural e históricamente asignado a las mujeres, al trabajo en sentido genérico. El orden sexual da cuenta de cómo el orden social está profundamente generizado, y de que la actividad económica se haya interpretado a través de categorías masculinas mediante valores androcéntricos. En sentido estricto, la naturaleza del trabajo tiene una clara base en el sexo, dado que, como indica Comas (1995), no es la división del trabajo lo que explica la subordinación de las mujeres, sino que es la desigualdad entre hombres y mujeres lo que se incorpora como factor estructurante en las relaciones de producción y en la división del trabajo. Desde este punto de vista, son las desigualdades de género las que determinan la posición que hombres y mujeres ocupan en la producción de la existencia, dado que todavía hoy el proceso de socialización está 
organizado jerárquicamente en torno a los géneros, el que produce y reproduce la vida humana, y el que produce y administra los medios que permiten la ampliación de la vida humana. Esta organización forma parte de un sistema de dominación masculina, y sin esta dominación, el patriarcado quedaría desenmascarado como una dominación arbitraria, y acabaría siendo derrocado por la rebelión, señala Castells (1998).

Por otra parte, cabe destacar que las políticas contra la pobreza y la exclusión han registrado una notable expansión en España durante los últimos años, principalmente mediante el desarrollo de un sistema centralizado de asistencia no contributiva y de un sistema descentralizado de protección general de los hogares más pobres a través de las rentas mínimas autonómicas. Aun así, persiste una ausencia de cobertura hacia las mujeres, cuya posición económica se viene deteriorando por su situación en el mercado laboral, en el trabajo doméstico y por el escaso acceso a la protección contributiva. Además, el estudio de la pobreza y de la exclusión social de las mujeres en España carece de una trayectoria consolidada; si bien existen referencias a la denominada feminización de la pobreza, se da un déficit generalizado desde una perspectiva de género. Un déficit inexplicable si asumimos que las diferencias de género configuran la vida de hombres y mujeres en aspectos fundamentales (por ejemplo, la distribución de ingresos, riqueza y tiempos), por lo que hay que transformar las relaciones de género si se quiere mejorar la situación de las mujeres; relaciones que son claves para comprender la situación social y económica de las mujeres, ya que al ser éstas las encargadas de realizar el trabajo doméstico, cuentan con un doble problema.

Por un lado, la dedicación al cuidado de personas mayores, enfermos o niños obliga a reducir o suprimir toda actividad remunerada. Ello supone una pérdida de la independencia económica, al mismo tiempo que se empobrece su red de relaciones sociales. Por otro lado, el hecho de que las mujeres sean dependientes del ingreso de sus cónyuges las sitúa automáticamente en una situación muy vulnerable, cuando cualquier acontecimiento vital afecte al cónyuge. Éste es el caso, señala La Parra (2001a, 2001b, 2002c), de los hogares monoparentales o de las viudas, que se encuentran entre los grupos más vulnerables a la pobreza de nuestra sociedad. Esta situación se debe a que en el momento en que el trabajo se convertía en un valor central, que afianzaba socialmente la existencia del individuo y se situaba así en el corazón de la ciudadanía libre e igualitaria, las mujeres se veían excluidas del trabajo, de la individualidad social y de la ciudadanía. Esta exclusión obedecía a que las mujeres fueron definidas como «dependientes» de los vínculos familiares y domésticos. Al convertirse la relación, con el trabajo y el empleo, en vínculo individual en la nueva organización social (puesto que dependía del contrato), no podían integrarse plenamente en ella. Así, durante mucho tiempo, el vínculo familiar será el que defina su vínculo con el empleo: o contribuyen a la producción de la empresa familiar, en la medida en que el marido es al mismo tiempo 
cabeza de familia y empresario, o acceden al mercado de trabajo asalariado, aunque sea bajo control del marido.

Desde una perspectiva política, Kabeer (1999: 130) plantea que un análisis de la pobreza desde la categoría de género supondría una aproximación en dos sentidos. El primero comprendería una interpretación más sensible hacia el género de las actuales estrategias contra la pobreza, que combinan incentivos de mercado e inversiones sociales. La evidencia empírica ha demostrado claramente que las limitaciones de tiempo y energía son especialmente constrictivas para las mujeres pobres, a causa de las exigencias mutuamente conflictivas de ganarse la vida y cuidar a la familia. El segundo sentido requiere una acción que elimine «las trabas estructurales que plagan y limitan todos los conjuntos de oportunidades de las mujeres; una acción que aborde las desigualdades de género en todas sus diversas formas como una cuestión de derechos humanos básicos. A tal efecto, la campaña del movimiento internacional de las mujeres, con el fin de que se reconozcan sus derechos como derechos humanos, debería ser considerada no como los intereses de un grupo vociferante pero sectario, sino como una contribución crítica e indispensable al buen desarrollo y, para algunas, una cuestión de vida o muerte». Y esto es así (y, por otra parte, resulta urgente) en tanto en cuanto la pobreza y la exclusión social se están acentuando en la actualidad por la degradación de las condiciones de empleo, un aspecto que explica la generalización de una insuficiencia relativa de recursos por parte de determinados tipos de mujeres para disfrutar de unas condiciones de vida aceptadas por la sociedad de referencia. Esta insuficiencia relativa de recursos afecta a las mujeres de forma muy desigual, y se explica por el hecho de que la responsabilidad de compatibilizar la vida familiar con la vida laboral recae aún hoy en las mujeres, lo que constituye el reflejo de la estructura patriarcal de la familia, que impone la inscripción social de las mujeres en el espacio doméstico, en el que están a cargo de las responsabilidades familiares. La fuerza de esta ideología familiar explica, así mismo, que el trabajo a tiempo parcial haya sido construido como una forma de empleo socialmente destinada a las mujeres y que, más allá del tiempo, se trata en realidad del estatus profesional y social de las mujeres, puesto que el trabajo a tiempo parcial se ha constituido esencialmente en su dimensión sexuada.

Esto explica también que, en las empresas, las mujeres sean consideradas trabajadoras que dedican sólo una parte de sus esfuerzos al trabajo y a la carrera profesional, y que sólo buscan un trabajo complementario al del marido. De aquí que la disponibilidad temporal sea un principio no gradualmente distribuido entre los géneros, y que se apoya en diferencias sociales que surgen por las desiguales distribuciones sociales del tiempo. Esta desigualdad seguirá siendo así en tanto en cuanto las mujeres sigan siendo fuerza de trabajo preferente para determinados puestos de trabajo, porque no han dejado de ser fuerza de trabajo más económica que los hombres; además, las mu- 
jeres son también más flexibles y, por tanto, convenientes en mercados laborales que son cada vez menos rígidos. En este sentido, el empleo a tiempo parcial vendría a ser la respuesta idónea de la sociedad, que no necesariamente de las mujeres, al tema de la reproducción de la propia especie tras la incorporación masiva de las mujeres a tareas productivas dentro del mercado de trabajo.

La concepción del empleo a tiempo parcial ofrecido específicamente a mujeres es el reflejo más evidente de la aceptación social de la ideología familiar, es decir, del modelo familiar del hombre como jefe de familia. Por otro lado, el empleo a tiempo parcial hay que situarlo históricamente en el contexto de declive del modelo ocupacional fordista, un declive que viene marcado por la contracción del empleo industrial y la "menor» segregación de género en torno al eje trabajo retributivo-trabajo doméstico. La segregación se supera por medio de dos vías; por un lado, la mayor participación femenina en el trabajo remunerado y, por otro, la doble presencia de las mujeres mediante el trabajo a tiempo parcial. Todo esto plantea que se tenga que analizar la relación salarial a partir de la categoría género, ya que la feminización de la clase asalariada desemboca en el incremento de los empleos poco cualificados en los servicios.

Éste es un análisis ineludible por cuanto el empleo asalariado y la asalarización no tienen el mismo significado para las mujeres que para los hombres, más aún cuando en la actualidad no se puede ocultar la nueva tendencia femenina de tratar de labrarse una identidad basada en la dimensión laboral; así, lo que caracteriza a nuestra sociedad ya no es la tradicional «retirada» de las mujeres en la relación con la vida profesional, sino la implicación femenina en el trabajo. En épocas anteriores, las actividades materna y doméstica bastaban para colmar la existencia femenina; no es éste el caso de nuestros días, en que la norma laboral se encuentra masivamente interiorizada en las mujeres, jóvenes o no. No obstante, la concentración de las mujeres en los empleos secundarios y mal pagados, y su posición de subordinación en el mercado de trabajo, deben interpretarse como una consecuencia del sistema de segregación sexo-género y de la ideología familiar patriarcal, conscientemente pretendidos.

Por otra parte, el proceso de feminización del trabajo asalariado da cuenta de que no hay ningún tipo de actividad que sea por naturaleza consustancial a la producción doméstica, y es que la forma en que las familias organizan su trabajo doméstico $y$ sus formas de convivencia no pueden ser entendidas sin atender a los cambios en las formas de vida de los distintos segmentos sociales que se derivan de su distinta vinculación con los empleos. Es decir, la relación salarial es un complejo mecanismo que establece una relación entre los procesos productivos y los procesos sociales que generan distintas formas de vinculación con el empleo; es una relación permanentemente revisada debido a los cambios que se producen en cada uno de estos dos espacios. Por ello, atender a los procesos sociales que articulan trabajo laboral y trabajo reproductivo 
implica analizar la división sexual del trabajo, que como concepto social abarca toda una estructura social, al indicar que el trabajo no se distribuye de modo neutral, que hombres y mujeres tienen puestos diferentes en el mundo del trabajo profesional y doméstico.

\section{Bibliografía}

Boserup, E. (1993). La mujer y el desarrollo económico. Madrid: Minerva Ediciones.

Brunet, I., y Pastor, I. (1997). Educación, trabajo y género. Barcelona: Llibreria Universitària de Barcelona.

Brunet, I*; Valls, F., y Belzunegui, A. (2008)+ «Pobreza, exclusión social y género», en Sistema, 207, págs. 69-85.

Brunet, I.; Valls, F., y Belzunegui, A. (2009). Gènere i creació d’empreses a Catalunya. Tarragona, URV.

Butler, J. (2001a). El género en disputa. México, D. F.t Paidós. Género y Sociedad.

Butler, J. (2001b). Mecanismos psíquicos del poder. Madrid, Cátedra.

Castells, M. (1998). El poder de la identidad. La era de la información: economía, sociedad y cultura. Vol. 2, Alianza, Madrid.

Chanéton, J. (2007). Género, pobreza y discursos sociales. Buenos Aires, Eudeba.

Comas, D. (1995). Trabajo, género y cultura. La construcción de las desigualdades entre hombres y mujeres. Barcelona: Icaria.

Foucault, M. (1991). Saber y verdad. Madrid, La Piqueta.

Foucault, M. (1983). Historia de la sexualidad. Madrid, Siglo XXI.

Kabeer, N. (1999). "Acción reproductiva, bienestar y desigualdad. Reflexiones sobre las dimensiones de género de la pobreza», en López I., y Alcalde, A. (coord.) Relaciones de género y desarrollo. Hacia la equidad de la cooperación. España, Libros de Catarata.

Laclau, E. (1993). Nuevas reflexiones sobre la revolución de nuestro tiempo. Buenos Aires, Nueva Visión.

La Parra, D. (2001a). «Vida familiar y empobrecimiento», en Tortosa, J. M. (coord.). Pobreza y perspectiva de género. Barcelona: Icaria.

La Parra, M. (2001b). «Una perspectiva de conjunto sobre el espacio social de la exclusión», en Moreno, L. (ed.), Pobreza y exclusión social: la «malla de seguridad» en España. Madrid: CSIC.

La Parra, D. (2001c). «Vida familiar y empobrecimiento», en Tortosa, J. (coord.), Pobreza y perspectiva de género. Barcelona, Icaria. 
De Lauretis, T. (1987). Technologies of Gender. Essay in Theory, Films and Fiction. Bloomington: Indiana University Press.

De Lauretis, T. (1991). «Queer theory: lesbian and gay sexualities», en Differences: A journal of feminist cultural studies, 3, 2, págs 3-18.

De Lauretis, T. (2000). Diferencias. Madrid: Horas y Horas.

Miyares, A. (2003). Democracia feminista. Madrid, Cátedra.

Molina, C. (2003). «Género y poder desde sus metáforas. Apuntes para una topografía del patriarcado», en Tubert, S. (ed.), Del sexo al género. Los equivocos de un concepto. España, Ediciones Cátedra.

Molina, C. (2007). «El feminismo socialista estadounidense desde la "Nueva Izquierda”. Las teorías del sistema dual (Capitalismo + Patriarcado)», en Amorós, C., y De Miguel, A. (ed.), Teoría feminista: de la Ilustración a la globalización. Vol. 2. Del feminismo liberal a la posmodernidad. Madrid: Minerva.

Sсотт, J. (2000). Los dominados y el arte de la resistencia. México, Era.

Tubert, S. (2003a). «La crisis del concepto de género», en Tubert, S. (ed.), Del sexo al género. Los equívocos de un concepto. España, Ediciones Cátedra.

Tubert, S. (2003b). «¿Psicoanálisis y género?», en Tubert, S. (ed.), Del sexo al género. Los equivocos de un concepto. España, Ediciones Cátedra. 